\title{
A Study on the Legalization of Local Intangible Cultural Heritage Protection
}

\author{
Li Lei \\ City of Urban Studies, Jianghan University, Wuhan 430056, China \\ 15479358@qq.com
}

Keywords: Intangible cultural heritage; Rule of law; Inheritance

\begin{abstract}
This paper explores the quality education function of intangible cultural heritage from the perspective of social culture. Through the analysis of the cognition and emotion of local intangible cultural heritage in the citizen group, It is believed that the inheritance of intangible cultural heritage is to promote the public. Cultural self-confidence, reshaping values and promoting national innovation ability are of great significance, and propose a legalization approach to inheritance and innovation of intangible cultural heritage.

UNESCO has placed special emphasis on the concept of world cultural memory in the process of protecting human oral and intangible heritage. It is considered that memory is extremely important for creativity and is extremely important to individuals and nations. The nations have found natural and cultural heritage, tangible and intangible heritage in their heritage, which is the key to finding themselves and the source of inspiration. ... preservation and inheritance of these historic testimonies, whether tangible or intangible cultural heritage, our aim is to awaken people's memories. Because human beings lose their cultural memory, they will lose their creation. This is our responsibility to future generations. [1] Whether it is traditional skills or beliefs, it is in a certain cultural ecology, and it is closely related to the region, history, etc.

Zhang Qingshan, secretary of the Party Committee and vice president of the China Academy of Art, once pointed out: "The principles of our national intangible cultural heritage protection work are: government-led, social participation, clear responsibilities, and formation of synergy; long-term planning, step-by-step implementation, point-to-face integration, Pay attention to practical results. That is to say, in addition to the responsibility of "government-led", each of us has the responsibility to protect. Only with social participation, the whole people consciously protect our own spiritual home, and our intangible cultural heritage protection work can really be done well. "[2] At present, the protection of intangible cultural heritage in our country has indeed achieved great success, and the protection of national intangible cultural heritage led by the Ministry of Culture.

The work formed a "two-wheel drive", and the work was broken, and social participation was significantly enhanced. The national intangible cultural heritage protection work has gone through ten years. In the past, it was mainly the top-down institutionalization construction. The list was reviewed, the inheritors were selected, and the national cultural and ecological protection zones were piloted to determine the working mode and proposed "rescue protection". The working concepts of "holistic protection" and "productive protection" have achieved important results. At the same time, there are more and more comments on the working methods and practical effects of "intangible" protection in the society. How to promote the relevant government administration has become the focus of social attention. How to let the general public hold deep feelings about local traditional culture and take more responsibility for the protection of China's intangible cultural heritage. This is a question worth pondering. Education is the foundation of cultural heritage, and law is the heavy weapon of cultural governance. The fundamental measure to truly activate the vitality and enhance the ability of non-legacy sustainable development is to establish a non-genetic inheritance system and a non-genetic inheritance rule of law system.
\end{abstract}




\section{The Importance of the Protection of Intangible Cultural Heritage in the Context of Globalization}

Intangible cultural heritage is an important carrier for enhancing the confidence of national culture In recent years, the two hot words "cultural self-awareness" and "cultural self-confidence" [2] have brought us deep thoughts. What is cultural self-consciousness and cultural self-confidence? Feng Huacai, vice chairman of the China Federation of Literary and Art Circles, believes: "The consciousness of culture is to be clearly aware. The significance of culture and civilization to human beings is indispensable." [3] At the same time, Mr. Feng further pointed out that "the cultural consciousness of intellectuals" and "the cultural consciousness of the country" are also quite instructive. The critics Deng Yuwen wrote an article: "If you want to revive Chinese culture, you must first have a sense of this 'rejuvenation'." It can be said that the so-called cultural consciousness is first and foremost a comprehensive and sufficient development of the history, reality and future of its own culture. Only in this way can we correctly handle the relationship between foreign culture and local culture. "Cultural self-confidence" is a concept closely related to "cultural awareness." When there is a lack of self-consciousness in one's own culture, it is easy to fall into a blind "cultural arrogance" or a pessimistic "cultural loss", which is undoubtedly a manifestation of lack of cultural self-confidence. Conversely, if there is no cultural self-confidence, when local culture and strong foreign culture encounter, due to the lack of a positive and open cultural attitude, nature can not obtain true cultural consciousness. Therefore, cultural self-confidence and cultural self-awareness complement each other and are indispensable.

The intangible cultural heritage contains rich traditional cultural codes, which is an important position to reflect the local characteristics of the national culture. It is especially important to maintain the characteristics of the nationality under the trend of world integration. The intangible cultural heritage is to highlight the traditional characteristics and beauty. The party's garden is a carrier of constructing a culturally confident and beautiful picture. Further, the intangible cultural heritage is a gem in the spiritual homeland of the Chinese nation. It is both a historical witness and a cultural heritage. It contains the unique thinking and spiritual values of the Chinese nation and embodies the vitality, creativity and imagination of the Chinese nation. General Secretary Xi Jinping has profoundly pointed out that we are born to be Chinese. The most fundamental thing is that we have the unique spiritual world of the Chinese people and the values that the people use and do not feel.

Intangible Cultural Heritage Education is an Important Way to Promote the Reconstruction and Construction of Socialist Core ValuesIntangible cultural heritage is an important carrier of traditional culture. The inheritance of intangible cultural heritage protection is an important task of cultural construction. Strengthening the education of intangible cultural heritage of college students is of great significance to improving the humanities quality and comprehensive quality of the citizens, and inheriting the national culture and The national spirit has an important moral education function. Incorporating intangible cultural heritage into the shaping of socialist core values will not only strengthen the citizens' learning and cognition of traditional culture and ideological and morality, but also enhance their moral cultivation, and also enable citizens to produce in the aesthetic enjoyment of intangible cultural heritage. The identification of his own national culture and national identity, and finally on this basis, promoted to the political identity at the national level, namely patriotism.

Many "non-legacy" projects have special significance for paying attention to people's inner harmony. For example, the inner harmony of the "Knowledge Culture" of Wuhan City relies on flesh-and-blood emotions, which can make people feel happy, affectionate, compassionate, compassionate, ideal, and belief. Because it inherits the spiritual experience, it can stimulate the resonance of our emotions. From this perspective, it is also the carrier of many kinds of emotional information and the repository of savings. And these can be a source of cultural innovation, such as Hua Mulan, Kung Fu Panda's film culture industry, the success of "eye-catching" precisely because they have the elements of Chinese tradition. The so-called "national talent is the world", precisely 
because of its unique culture, it has the source of rejuvenating vitality, and it is also the inexhaustible source of the citizens to achieve cultural innovation. [4]

Intangible cultural heritage can enhance citizens' cultural innovation and entrepreneurship Intangible cultural heritage has many values for human beings, including memory value, inheritance value, aesthetic value, genetic value, academic value, and economic value. For a specific intangible cultural heritage, its project Value also has its own particularity. For example, the economic value of the intangible cultural heritage of traditional crafts, if combined with the work and life of the citizens, the training of non-material culture related to traditional skills, can expand the horizon and direction of building a harmonious society, mainly reflected in the following aspects: Material cultural heritage tourism economy (for citizens in economic management, cultural industry management or tourism industries), intangible cultural heritage brand advertising economy (for economics, cultural industry management, advertising and other industries), intangible cultural heritage Technology (for citizens in the fields of fine arts, musicology, etc.), patent economy (for citizens in the economic management industry), etc.

In addition, the intangible cultural heritage also has scientific value, harmonious value and aesthetic value. In the promotion of the cultural quality of the citizens, through the social training related to the traditional intangible cultural heritage, they have rich historical and cultural knowledge and excellent scientific literacy. The unique cultural and artistic aesthetic ability is the background color, so as to fully experience the social education of the traditional art and non-material culture. In terms of entrepreneurial innovation, practitioners in relevant industries understand both culture and economic management, thereby enhancing their strong social practice experience and forming an overall quality and ability. Give full play to the educational functions of traditional intangible cultural heritage, and forge the special talents for the protection, inheritance, research, management and development of intangible cultural heritage, through their relevant industries in government, society, research institutions, schools and even training institutions. The role of "reporting" the management and propaganda of intangible cultural heritage: promoting the role and positioning of the government in the protection of intangible cultural heritage, better improving the quality of life of cultural heritage inheritors, and promoting the realization of relevant protection measures, By enhancing the ability of the whole society to work and start businesses, the whole society can demonstrate the meaning and function of intangible cultural heritage.

\section{Citizens' cognition and countermeasures on intangible cultural heritage}

Citizens' cognition of intangible cultural heritage According to the survey and interview data, the citizens of a certain district of Wuhan are more interested in the intangible cultural heritage of the city, but the concept and scope of the intangible cultural heritage are not clear, and their cognition has obvious pragmatism and utilitarianism. There is a certain gender difference in the tendency. They agree that the development of tourism is conducive to the protection of intangible cultural heritage, and the hope is placed on the local government to increase investment. At the same time, it should be "started from the doll" and should be carried out in adolescents. Cultural heritage local education, under the existing protection and inheritance work protection framework, absorb more social forces to participate in, in order to fundamentally overcome the difficulties in the protection and inheritance of intangible cultural heritage. This shows that college students have a certain understanding of the education and inheritance of intangible cultural heritage.

Other citizens' understanding of intangible cultural heritage mainly focuses on the shallow level of perceptual knowledge, lacking understanding and thinking at the academic level. Although the media has carried out more publicity on non-legacy protection, most of the projects have only stayed at the stage of establishment of the list because the work of combing, analyzing and categorizing the projects has just started. The evaluation and identification research work has not yet been fully carried out. The database of intangible cultural heritage resources needs to be established, and the platform for protection and development needs to be built. These are all necessary things for the census work system and the basic work for the protection of intangible cultural heritage. Coupled with the recognition and protection of intangible cultural heritage is a 
professional work, the city's professional management talents in this area, or "non-legacy" inheritors, and even cultural communication brokers are very scarce. This has greatly restricted the protection, inheritance and utilization of "non-legacy".

The survey also found that many citizens believe that some non-legacy projects, especially traditional art projects under the impact of the market economy, such as Cao Zhengxing kitchen knives, are somewhat old-fashioned, outdated, and now in the world of "acousticization", therefore, People's enthusiasm for non-existence is hard to last, not to mention the sacred reverence and "cultural self-confidence" in their feelings. From this point of view, we should give full play to the local resource advantages, promote the government, universities, and social linkages to open intangible cultural heritage courses in colleges and universities, integrate various resources, and use creative means to encounter those traditional non-legacy projects in the inheritance. The skills of "Bao Zhi Gao Ge" can be spread throughout the society, thereby improving the cultural survival ecology of intangible cultural heritage projects, infecting the aesthetic culture and literacy of all citizens, and actively raising the awareness of the intangible cultural heritage of the whole society. Provide the necessary talent pool for the sustainable development of intangible cultural heritage. For example, the School of Art and Media of Wuhan Software Engineering College has established a lighting and color art studio. With the goal of "inheritance and protection", Mr. Luo Guangwen, a folk art master, is invited to the school to carry out non-legacy cultural lectures and practical teaching guidance to create traditional technology and The combination of modern technology and lighting talents. Through the efforts of colleges and universities, to produce a "butterfly effect", thus radiating the whole society.

Enhance the public's need for cognition and emotional identification of intangible cultural heritage The social function of intangible cultural heritage is multi-dimensional, ranging from individuals to communities to large ethnic groups and countries. In addition to its importance in developing cultural diversity and promoting the diversity and sustainable development of the world's various ethnic cultures, it is of great importance to pay attention to itself. Special cultural identity and cultural individuality, the establishment of unique national values, psychological structure, temperament and emotions need to rely on the identification, maintenance and revitalization of their own intangible cultural heritage. From the perspective of the inheritor, the value of the intangible cultural heritage is independent in terms of the historical sense of belonging, aesthetic value and economic benefits provided by the intangible cultural heritage. At the same time, the value of the intangible cultural heritage is not only for the creation of non-material inheritance. The main body of cultural heritage is beneficial and meaningful and valuable to people outside the group. "Culture is an invisible force that drives people to approach it and thus unites everyone."'[5]

From this point of view, the inheritance and protection of intangible cultural heritage protection has a long way to go. While actively participating in the protection of intangible cultural heritage, effective measures should be taken to do a good job in educating the citizens on the intangible cultural heritage. It should be noted that culture has its own "metabolism", which is constantly adjusted and developed in different natural and social environments, showing different faces. China is a big country with cultural heritage resources. Chinese culture is becoming more and more concerned by the world, but it is far from the cultural innovation power of the West. The world trend is still a world cultural power dominated by a strong economic and cultural background. In particular, the survival of China's intangible cultural heritage is facing an embarrassing situation. The reason is not only the survival predicament of the non-material cultural project itself, but also many social groups following the world trend "Hazhhahan", indifferent to traditional culture. In particular, it is emotionally indifferent to the intangible cultural heritage of traditional crafts, with little cognitive knowledge and little attention.

As American anthropologist Salins thinks, "In the postmodern society, the whole world has changed. The biggest change is that traditional culture and modern culture are no longer a contradiction, but can be integrated. The forces that promote each other. Then there is the emergence of "native modernization." [6] That is to say, modern culture is derived from traditional culture. Traditional culture does not mean "old soil", but is accompanied by cultural innovation. It 
is a new life charm, and this charm is more characteristic because of the foundation of traditional culture. The so-called "nationality is the world."

After all, industrialization and modernization are a double-edged sword. Social development has brought many conveniences to human beings, and it has also paid the price of social progress for human society. These negative effects have brought potential threats to human culture. It is self-evident that the traditional intangible cultural heritage provides a steady stream of resources for contemporary Chinese cultural innovation and development. It cannot be said that the promotion of certain handicraft production methods and certain outstanding ingredients in the traditional way of life in the inheritance is also one of the important ways that traditional society brings us to the harmonious and healthy development of contemporary society.

For example, the traditional art $\mathrm{Su}$ Hengtai oil paper umbrella has a distinct historical and cultural value. Su Hengtai is one of the 100-year-old stores that still existed since the opening of Wuhan. It is known as the four famous famous products of Hankou, "Ye Kaitai Chinese Medicine, Laojiu such as Comb, and Niu Tongxing Scissors". With far-reaching influence, Su Hengtai is the spokesperson of "Wuhan Made" oil-paper umbrella, which has important historical value. Su Hengtai oil paper umbrella classical nostalgia, rich cultural connotation, oil paper umbrella and "children" homophonic, to show that the children are blessed; umbrella face open, meaning open branches and leaves; umbrella bones, bamboo newspapers safe; umbrella shape is round, meaning Happy reunion, Jianghan Plain is circulated when both men and women buy Su Hengtai umbrella, male holding red, female holding blue, meaning "red male green female, happy marriage", blending folk culture, festival culture, marriage customs culture. Just as the "big red lanterns hanging high" in the north made people impressed with the lanterns in the north, and the rainy in the south, the umbrella became synonymous with the beautiful things that inherit historical memories.

Taken together, each intangible cultural heritage is specific and special, depending on ethnicity, language, time, space, and inheritance. Intangible cultural heritage is an intergenerational culture. It is the result of the continuation and development of the previous generation culture. It is a culture created by generations and generations. This creation is a culture that is generated, passed down and developed in the process of intergenerational inheritance. Under the domination of economic GDPism, rapid urbanization takes the foundation as the dominant idea, focusing on the expansion of urban scale and the simple agglomeration of the population, large-scale urban building, forced division of rural land, demolition of rural dwellings, Homogeneous village reconstruction and disordered villages

Management has eliminated the material carrier and space of traditional village culture. This way of transforming rural areas into small and medium-sized cities and towns and forcing urban characteristics into traditional rural life is a visible constructive destruction for intangibles, which is reflected in the shovel of geospatial space and the demolition of non-legacy. The surviving carrier and the historical roots of the legacy. [7] Under the background of profound changes in the environment of social formation, lifestyle, etc., the development of intangible protection and inheritance education is the expression of the wisdom and creativity of the whole society, and the dynamic inheritance in practice. It is essential to continuously improve the level of contemporary practice, to protect and enhance the vitality of the inanimate, and to maintain and enrich the diversity of human culture.

The rule of law construction and practice of citizens participating in the protection of intangible cultural heritage The insubstantial and complicated nature of intangible cultural heritage makes it difficult to operate and enforce it. It needs to be handed over and cross-protected with other laws. For example, the protection of folk literature involves the Copyright Law, and the protection of folk arts and crafts involves the Cultural Relics Law. The "Regulations on the Protection of Traditional Arts and Crafts", the protection of the "old name" refers to the "Trademark Law", and if it is otherwise illegal, it will also involve the Criminal Law. The protection of rights and interests and intellectual property rights are the most "from the perspective of intellectual property rights, traditional knowledge, folk literature, traditional names, and modern intellectual property objects such as inventions, works, trademarks, etc. have certain similarities in technical 
quality and economic character. Such as creativity, practicality, etc., it has intellectual property significance." [8] Because "non-legacy" is a special attribute of traditional culture, it is included in culture and can not clearly divide the rights relationship, and its rights are also in a vague state, which makes the legalization of "non-legacy" legal protection difficult. In order to scientifically implement the "Non-legacy", we must proceed from the following aspects:

From the perspective of legislative principles, government management departments should actively promote classification protection The locality has unique cultural characteristics and rich content and form, so it can promote college students to correctly understand folk beliefs, cultivate national pride and strong sense of social responsibility. It has many connotations and values of ideological and political education. The process of subtle influence affects the way of thinking and values of the citizens, thus cultivating the fine tradition of patriotism and love for the family. It is necessary to take various measures to improve the public's awareness and interest in the protection of intangible cultural heritage. Protection is not just a national act. Emphasis is placed on strengthening the participation of "non-legacy" protection work (see Articles 8, 9 and 10), "The state encourages and supports citizens, legal persons and other organizations to participate in the protection of intangible cultural heritage" (Article 9). Intangible cultural heritage originated among the people, and should also return to the "live" protection of people's lives, and then develop. The government-led protection of intangible cultural heritage protection is the basic guarantee. It refers to the conscious and spontaneous recognition and participation of the people. The "non-legacy" can last and be full of vitality. Legal and other organizations involved in the "non-legacy" protection work is both a license and a drum Reed, whether it is the input of economic power and talent. The involvement of non-governmental forces can help increase the influence of "non-legacy" protection work and activate the protective atmosphere of public participation.

Focus on classification protection. Formulate protection and inheritance and utilization plans for classification and classification, grant and recognize the rights of intellectual property rights of "intangible cultural heritage" and strengthen management; strengthen the protection of endangered "non-legacy" projects, and consider setting up "endangered" non-legacy declarations. "Green channel for approval, guidance," can also use the "registration system" to strengthen the priority protection of "non-legacy", such as certifying the identity of the manual craftsmanship, recognizing its quality, and avoiding being avoided in the market. "Confused" to achieve real value and facilitate timely and effective protection.

From the perspective of legislative objects, it is necessary to ensure public participation. Due to the popularization of the Internet, the thoughts, values and aesthetic trends accompanying the "Hundred Flowers Blossom" gradually came into being. Multiculturalism and values are reflected in the fact that people can choose their favorite products based on their own preferences and in combination with the information they have acquired. ------ Consumption of the cultural products they need; and the daily routine of aesthetics and the aestheticization of daily life are becoming another major feature of the creative era. Diverse choices and vibrant daily life can attract the eyes of creative people. They think that it is the responsibility of art to let people feel beauty in daily life, and it is also the need of creative age. In the book "Visual Culture", Howells proposed: "The use of feature codes or symbols is not limited to religious or mythological works of art, it also continues into everyday life."[10]

Encourage citizens to learn the legislative content of intangible cultural heritage through various media, gradually form correct value judgments, and gradually realize that intangible cultural heritage contains rich educational values and norms and roads of rule of law, and cultivate their own national spirit. Sharpen the character of one's will, stimulate their own innovative ability, cultivate their own aesthetic consciousness, and enhance their own rule of law. Such as the periodic reporting system for the protection of national representative projects, the supervision system, the reward and punishment system and the "exit mechanism". However, in addition to measures such as recognition, rewards, and subsidies, measures to strengthen supervision and management are aimed at the situation of "unfair competition" and "over-utilization" in the real world, and also to further 
prevent the "non-legacy" from being damaged again in incorrect protection. Have more detailed penalties and investigation measures.

From the perspective of legislative content, fully tap the treasure house of local cultural characteristics Local non-research projects are splendid, such as Wuhan's unique characteristics of intangible cultural heritage such as dragon boat and Guqin art. It has a strong national style and characteristics, and has strong regional, national, diverse and entertaining characteristics. While maintaining the independence of the national culture, it can adapt to the development of modern society, renew its vitality and vitality, and gradually promote local traditional culture to the whole country and to the world. There are also some non-legacy projects of traditional skills that can propose from the perspective of design innovation through materialization, modernization and systematic approaches and means to create a reasonable way of inheritance, living environment and cultural ecology for intangible cultural heritage, so that it adapts to the contemporary The new production methods, lifestyles and aesthetic concepts of the society will enhance the employment and entrepreneurship of the citizens. These are all non-legacy projects with realistic significance. In the face of the dilemma of environmental change, ecological loss and lack of inheritance, by strengthening guidance and encouraging practice, it is conducive to enhancing the national identity of the citizens and realizing cultural diversity. The implementation of local legislative power and autonomy also reflects the state's respect for national autonomy. It tries to avoid the implementation of local laws and related legislation, copying or copying the corresponding legislation of the provinces and cities in the Mainland. The implementation of legislation on provincial conditions and market conditions is more effective than the implementation of national laws. Because local legislation is the implementation and implementation of national legislation in various administrative regions, some legislations have more creative norms than national legislation, and are more in line with local realities. In particular, let local citizens participate in their legislative activities so that they can better understand and understand the content of legislation, and more in line with the requirements of local social and cultural development.

From the perspective of the legislative model, we can fully learn from the international advanced legislative system. Relevant scholars put forward the main models and systems of non-legacy legislation in China through the analysis and research of different non-legacy legislative models in the world today. There are three types: unified legislative model, separate legislative model, and infiltration legislative model. The unified legislative model is used to regulate and adjust the protection of non-legacy administrative laws. The conventions and treaties on non-legacy protection formulated by international organizations today basically adopt a unified legislative model, such as the Cultural Heritage Protection Law promulgated by Japan and South Korea. Wait. The so-called separate legislative model refers to a legislative model for separately protecting different forms of intangibles through a single-line administrative law normative document. Countries adopting separate legislative models have formed separate legislative models with their own characteristics in combination with their own political, economic, and management systems. For example, the United Kingdom has separately legislated for different levels of protection objects such as monuments, buildings, protected areas, folklore, folk customs, and historical ancient cities. The so-called infiltration legislative model refers to the infiltration of the content of the non-legacy administrative law protection norms into other private law norms, that is, the relevant intellectual property law and other civil laws are incidentally stipulated in the relevant non-legacy administrative law protection, such as India's The Biodiversity Act, Tunisia's Literary and Artistic Copyright Act, etc. Finally, the author also points out the possibility of adopting the non-legacy unified legislative model in China's existing national conditions. He believes that because China implements a "one yuan multi-level" legislative system, the adoption of the non-legacy-legislative model can make China's State Council, A number of legislative bodies, such as ministries and commissions, and local people's congresses, jointly implement non-legacy laws and regulations, which can be implemented concretely or modified.

Therefore, through active access to the support of local governments, the whole society has made concerted efforts to make intangible cultural heritage a high-quality legalized educational resource, 
so as to effectively integrate into all major aspects of social governance, thereby promoting the protection of intangible cultural heritage. inherited. Strengthen the cultivation, education and talent injection. The provisions of the "Non-Legacy" on "education" are a bit thin. Non-legacy is included in the relevant courses to enter the campus or encourage students to participate in the "non-legacy" extracurricular activities. As part of the excellent traditional culture education, the young people will increase their interest in "non-legacy" and activate the traditional cultural atmosphere. This can not only cultivate potential inheritors, but also the best way to inherit and promote traditional culture, so it should be strengthened. In addition, the injection of professional talents is also very necessary, attracting talents to "employment", participating in "non-legacy" protection, planning, promotion and other new talents will use professional knowledge to help the old tradition to rejuvenate. Through effective measures to promote the coordinated development of non-legacy education, protection and inheritance and social rule of law, and finally build a new path of cultural consciousness and cultural self-confidence.

\section{References}

[1] Bianan.Wu, Theory and Method of Intangible Cultural Heritage Protection, (Culture and Art Publishing House,china, 2010), p16.

[2] Zhongmou Zhang, editor. Inheritance of Intangible Cultural Heritage, (Culture and Art Publishing House, china, 2010) p 1

[3] Heping Xie, editor; Cao Ping, deputy editor of Yao Leye, university cultural consciousness and cultural self-confidence, (Sichuan University Press, 2012)p 8.

[4] Changhong Miao. Yellow River Civilization and Sustainable Development - The 5th Series, ( Henan University Press, china, 2013)p196.

[5] Xiaotong Fei. Cultural and Cultural Consciousness. ( Group Press, china,2010)p34.

[6] Lili Fang. The "Protection" in the Perspective of "Cultural Consciousness". (Times Huazhi Office, china, 2015)p355.

[7] Zhongyuan Xie. Research on non-genetic inheritance and protection of Foshan in the post-posturing period, (Sun Yat-sen University Press, china, 2015)p 15.

[8] Yonghe Yan. Intellectual Property Protection of Intangible Cultural Heritage, Legal Experts Discuss Legal Protection of Intangible Cultural Heritage, Guangming Daily, August 10, china ,2010).

[9] Zhiyao Ma, Ruizhe Sun. Cultural creativity and non-legacy protection,( Tianjin University Press, china, 2014)p5.

[10] Yueming Rong, editor-in-chief. Frontiers of literature and culture theory, (Shanghai Academy of Social Sciences Press, china, 2016)p303. 